\title{
The Evaluation Conversation A Path to Impact for Foundation Boards and Executives
}

Patricia Patrizi

Series Editors Patricia Patrizi Kay Sherwood Abby Spector

October 2006

To download for free, log on to the Foundation Center's web site: foundationcenter.org/gainknowledge/practicematters/ 


\section{About the Project}

Practice Matters: The Improving Philanthropy Project presents a series of papers that explore, and ultimately aim to advance, key practices in philanthropy. Written by national experts, the titles address ten core philanthropic practices: using intermediaries, sponsoring policy commissions, effecting community change, attracting and managing talent, creativity in grantmaking, using ideas in building a field, building organizational capacity, communications for social good, foundation partnerships, and evaluation.

The series starts from the premise that philanthropy, as a field, needs to understand good philanthropic practice much better than it does now, and that there is a discernible craft that can be taught and improved. The papers and accompanying discussion guides are available for free download at the Foundation Center's web site at foundationcenter.org/gainknowledge/practicematters/.

Practice Matters: The Improving Philanthropy Project is supported by the California Endowment and the Robert Wood Johnson, Ewing Marion Kauffman, John S. and James L. Knight, and David and Lucile Packard Foundations. The project is housed at the OMG Center for Collaborative Learning in Philadelphia. Patricia Patrizi, Principal, Patrizi Associates, directs the project. Abby Spector serves as project manager and Kay Sherwood is the principal manuscript editor.

For more information, please contact:

Patrizi Associates

1528 Walnut Street, Suite 805

Philadelphia, PA 19102

(215) 732-2200, ext. 235

practicematters@patriziassociates.com

\section{About the Foundation Center}

Established in 1956, and today supported by hundreds of foundations, the Foundation Center is the nation's leading authority on organized philanthropy. It maintains the most comprehensive database on U.S. grantmakers and their grants, conducts research on trends in foundation growth and giving, and operates education and outreach programs. Thousands of people visit the Center's web site each day are served in its five regional learning centers and its national network of Cooperating Collections. For more information, visit foundationcenter.org or call (212) 620-4230.

For more information, please contact:

The Foundation Center

79 Fifth Avenue

New York, NY 10003

(212) 620-4230

foundationcenter.org

Copyright ( 2006 by The Foundation Center. All rights reserved.

ISSN 1545-6781 


\section{Editors' Note}

Foundation investment in evaluation has increased in recent years, but philanthropy has yet to reap the full benefit. In many foundations, evaluation has only a marginal role and is seen exclusively in terms of measurement at the end of funded programs. In her paper, The Evaluation Conversation: A Path to Impact for Foundation Boards and Executives, Patricia A. Patrizi challenges foundation leaders to rethink the role of evaluation, and turn it into a vital institutional tool to achieve philanthropic purpose and improve strategy.

How can this be done? Patrizi urges foundation leaders to launch an evaluation conversation, in which CEOs and board members, assisted by evaluators, engage in an ongoing, collaborative inquiry that explores the key questions that underlie a foundation's investments: What are we trying to accomplish? What can we do that has the greatest probability of getting us there? What is already known about how to get there? Are we committed to following through and making adjustments in programs, if needed? Are we willing to talk about our failures, as well as our achievements? The goal is to create more accumulated knowledge, more purposeful evaluation, and better information for better decisions.

Patrizi discusses how to use evaluative inquiry to examine seven dimensions of foundation strategy. She recommends ways to start the conversation, specific questions for board members and executives to ask, and indicators that foundations can use to gauge their progress along the way.

Readers should note that this article is written as a discussion guide, and therefore does not have a separate manual with it. 


\section{Beyond Measurement ${ }^{\prime}$}

Without probing clarity and open inquiry, foundation attempts at accountability will be merely symbolic.

It's feet-to-the-fire time in philanthropy. Foundation effectiveness and accountability have long been on the philanthropic agenda, but the issues have heated up in recent days. Philanthropy associations and think tanks are pushing accountability initiatives. Nonprofits are struggling simultaneously with cutbacks from the public sector and intense pressure from funders for documented outcomes. Stories in the national press are highlighting abuses of power and resources at a few foundations. Grantees are increasingly critical. And Congress has taken up the matter.

At the behest of the U.S. Senate Finance Committee, Independent Sector, a coalition of more than 600 charities and foundations, convened a national panel on accountability and came back with recommendations aimed at strengthening governance, ethical conduct, and effective practice. One key recommendation: "Every charitable organization should, as a recommended practice, provide detailed information about its programs, including methods it uses to evaluate the outcomes of programs, and other statements available to the public through its annual report, website and other means." (Italics added.) ${ }^{2}$

This is an important statement, highlighting the critical role evaluation plays in making philanthropy accountable. It should be heeded by all foundations. But how much will the adoption and demonstration of evaluation methods, metrics, indicators, and benchmarks alone really do to solve the effectiveness puzzle? Before determining measurement, we need to begin a more critical conversation regarding what we are trying to achieve - and what information is needed to get us there, as well as signal when we've arrived. What knowledge can help a foundation become excellent at what it does? One reason evaluation has been sidelined in philanthropy is that it frequently is seen as the exclusive domain of technicians commissioned to produce clear and simple metrics, rather than as a path for leaders to achieve purpose and improve strategy. Foundations that treat evaluation as the exclusive job of the evaluation director, and solely as a matter of measurement, squander its potential.

It's time for a new use of evaluation, one that directs our thinkingopenly and often - at the fundamental questions that underlie a foundation's investment: What are we trying to accomplish? What can we do that has the greatest probability of getting us there? What is already known about how to get there? Are we committed to following through and making adjustments if needed? And are we-and this is the question at the 
core of that lightning rod issue, accountability-willing to talk to others about what difference we've made ... and where we've failed?

These questions and issues are not for evaluation specialists to examine alone. They are for leaders, and they are not being asked enough. A fully accountable philanthropy would do better at grounding its work in rigorous practice knowledge; explaining not only funding strategies but the premises behind them; acknowledging institutional values and biases; and admitting what we don't know. A fully accountable philanthropy would offer more than surface data disconnected from the reality of issues and organizations that foundations support and from the purposes and values that frame their decisions. We owe it to our constituencies to be this clear-minded about where we are headed and why. Without probing clarity and open inquiry, foundation attempts at accountability will be merely symbolic. 


\section{Where's the Conversation?}

This notion of accountability through inquiry as much as measurement goes for grantees in the same way it goes for foundations. Indeed, the blanket suggestion to "tell us how you evaluate" - which is a core element of the Independent Sector recommendation to charitable organizations-takes me back nearly 20 years. As a new director of evaluation at The Pew Charitable Trusts, I used to make a similar recommendation to grantees: "Tell us how you will evaluate the success of your grant." This was, of course, a reasonable and important request. The problem is that it wasn't the right request. What got lost was the question of how purpose would be achieved.

In response, rather than demonstrating serious consideration of what could be different as a result of the grant, grantees would predictably propose a process - "We will hire an adjunct faculty member at a local college to assess the effects of the grant," or "We will conduct a pre- and post-survey" — without exploring what they really wanted to know. Evaluation was often treated by grantees - and, for that matter, by foundations - as a box to be checked, a technical solution to be outsourced to specialists. No one owned the more critical question because it was never put to grantees: What does success (for both parties) look like, what do we need to know to get there, and how will we know if we have succeeded? These exchanges drove home for me the importance of grantmakers and grantees, as well as colleagues within a foundation, having an authentic dialogue about a grant's purpose and what would constitute satisfactory outcomes for both sides. They also remind me how rarely-in more than 18 years of work in philanthropy-I've seen that dialogue happen.

What is needed, between foundation and grantee, within foundations, as well as in the field at large, goes past developing measurement methods and into a deeper and more nuanced evaluation conversation. Moving beyond agreement to measure, this conversation can and should be a collective search for value and an exploration of how evaluation can help. The best work of evaluation comes not just through a tight set of metrics but via a real, ongoing, dynamic dialogue among professionals, where tensions are raised, tricky issues discussed, hard questions asked. Are you having such a conversation? If you're a grantmaker, executive or board member and are like most foundation professionals, the answer is likely to be "no." But to maximize evaluation as a vital institutional tool for real accountability and effectiveness, to make the wisest decisions at every level of foundation practice, the answer needs to be "yes." 


\begin{tabular}{|l|l|}
\hline \multicolumn{2}{|c|}{ Moving to a New Model } \\
\hline \multicolumn{1}{|c|}{ Typical Approach } & \multicolumn{1}{c|}{$\begin{array}{c}\text { Evaluation } \\
\text { Conversation Approach }\end{array}$} \\
\hline $\begin{array}{l}\text { Evaluation focused on } \\
\text { measurement }\end{array}$ & Evaluation focused on inquiry \\
\hline $\begin{array}{l}\text { Evaluation as a specialist's } \\
\text { responsibility }\end{array}$ & $\begin{array}{l}\text { Evaluation as a leader's } \\
\text { responsibility }\end{array}$ \\
\hline $\begin{array}{l}\text { Evaluation as discrete, outsourced } \\
\text { function }\end{array}$ & $\begin{array}{l}\text { Evaluation as ongoing, collective } \\
\text { responsibility }\end{array}$ \\
\hline $\begin{array}{l}\text { Evaluation at final stage of } \\
\text { grantmaking }\end{array}$ & $\begin{array}{l}\text { Evaluation at every stage of } \\
\text { grantmaking }\end{array}$ \\
\hline Evaluation on the margins & $\begin{array}{l}\text { Evaluation at the center of } \\
\text { everything we do }\end{array}$ \\
\hline
\end{tabular}




\section{The Leader's Job}

Foundation leaders have missed the boat in terms of managing their organizations with the kinds of information that we would expect corporate executives and government managers to have at their command.
Where do foundations have real purchase? We don't deliver services. We don't run campaigns. We don't develop policy. What we do have is the power to use our knowledge to effectively and strategically distribute resources. The great opportunity foundations face is to activate and apply the knowledge base in a field to make investments with impact-an opportunity we have not yet seized. Foundation leaders by and large have missed the boat in terms of managing their organizations with the kinds of information that we would expect corporate executives and government managers to have at their command. Instead, responsibility for that information has been delegated and outsourced-most prominently in the form of an increasingly marginalized and specialized evaluation function. This is a mistake. Evaluation and the mission-critical information it can generate should, with assists from evaluation personnel, be an executive and board responsibility.

One reason evaluation is typically not seen as a leadership duty is the sheer complexity of philanthropy's work, with its seemingly endless demand for new information. For executives and especially board members who oversee multipurpose foundations, the knowledge required to make wise decisions can be downright overwhelming. Foundations are often dealing with intricate human systems that take on intractable social problems in constantly changing contexts. Even the most carefully crafted strategy will quickly become obsolete if not reviewed against changing circumstances, regularly and mercilessly. It comes as little surprise, then, that many leaders resort to delegating the responsibility for getting a good handle on that information to program officers, evaluation officers, and consultants. Evaluation expertise is important for many reasons, of course, and in many cases such delegation makes sense. But to truly advance accountability, a foundation's leaders must take responsibility for the core questions that evaluation raises.

Distanced from the source of authority and hearing their directions only third-hand, many evaluators respond to the most vehement imperative and the largest complaint. They take the charge to make their information "short" and "simple" seriously, and leaders, typically the source of that charge, tend to embrace these improvements through new forms of presentation, in lieu of more complex improvements in strategy knowledge. A counterproductive dynamic can emerge. Executives, perhaps feeling ill-informed about the field and uninvolved in programmatic 
conversations, as well as distanced by dense evaluation products, may not ask critical questions of program staff. Program staff, feeling pressured to get the commitment of busy executives to program strategies that have been developed at a far remove from the executive office, may minimize or even overlook information that runs counter to the strategy of choice. Meanwhile, evaluators, taking their charge from program staff, often address questions that are of marginal ultimate interest to those in leadership positions. The frequent result: bad strategy and irrelevant evaluations. 


\section{Lure of Simplicity}

When evaluation is reduced to metrics, it can get oversimplified to a harmful degree among foundation boards and executives.
As a foundation's responsibility for practice knowledge becomes increasingly offloaded and marginalized, another development can come into play: fixation on the clear and simple at the expense of the complex and dynamic. While many leading businesses and most business schools have started to eschew planning approaches that embrace linear models of cause and effect and engineering systems of inputs, outputs, and outcomes, foundations have embraced them with a fury. The job of many evaluation directors has been narrowed to the production of metrics. Logic models, report cards, executive dashboards abound-simplified processes that produce simplified information. These can serve the important purpose of articulating what a foundation intends, in the broadest strokes, but they often suffer because of ill-founded assumptions and simple, even wishful thinking. More importantly, they tend to reify a belief that if a foundation (or its grantee) does $\mathrm{X}$, then $\mathrm{Y}$ will necessarily result, when such direct cause-effect relationships are rare. Metrics can force an assessment of whether supported strategies match up to a foundation's goals. Yet here leaders often fail to take the vital next step of questioning whether the strategy is sufficient and what it might take to be crafted with greater likelihood of impact.

The monkey wrench in the linear planning machine is on-the-ground change. What happens if things alter course, as they often do in the evershifting fields in which philanthropy does its work, and suddenly your clear position runs aground? What happens when you haven't created the mechanisms to stay alert to changes, systematically revisit your plan rather than have it gather dust on a shelf, and ensure your openness from the beginning to alternative interpretations and points of view regarding the complex problems you aim to solve? Over-reliance on linear, one-time plans can obscure problems in fields where outcomes are highly uncertain at the time of a grant award. In many situations, foundations are operating, at best, on educated guesses, and obtaining information as strategy unfolds is crucial. Real-time pattern recognition and adaptation to change may be one of evaluation's most important functions and outcomes_-and its least appreciated.

When the whole of evaluation is reduced to metrics, it gets oversimplified to a harmful degree among foundation boards and executives. Social change is as difficult an endeavor as any organization can aspire to achieve. It requires the wisdom of generations and commitment of multiple actors. 
Rarely can it be distilled down to the simple fact sheets that boards seem to request with increasing frequency. While a few indicators can seem to provide clarity, they usually reveal little about underlying assumptions. And they say even less about the interdependence among actors that is crucial to achieve positive results. Those on the front lines of service delivery understand this reality.

The lure of simplicity can keep board members and others from becoming fully informed and involved. We need to ask: What is the benefit of board members being in the dark about how hard it is to change outcomes for children in poverty in America or to increase food security for farm families in Africa? Why is it important to accede to some board members' demands to simplify reporting on how a single foundation is diminishing the disparity between the "haves and have-nots" in achieving success, when such impact is nearly impossible to calculate? And then we need to ask: What is the likely cost of keeping board members and management ill-informed about the work that they oversee? Experience at NASA illustrates that reports attempting to simplify complex problems down to a few indicators are likely to overlook seemingly insignificant factors, such as the effect of loose tiles on the surface of a space shuttle_-insignificant, that is, until their effects prove deadly. ${ }^{3}$ 


\section{Evaluative Inquiry}

By understanding evaluation as ongoing institutional inquiry, rather than as discrete, outsourced measurement, we can bring it in from the margins to the heart of the foundation enterprise.
The impulse to outsource evaluation, the tendency to see it exclusively in terms of measurement, the marginalization of knowledge and information responsibilities in the halls of foundations, the trend toward managing to metrics rather than to change-these developments reflect a model of evaluation that is becoming obsolete and preventing foundation leaders from making the most of this important discipline. We need a complete reconfiguration of the way evaluation is used in foundations, large or small, private or public, young or old. For the evaluation conversation to happen more often, more productively, and more widely in these organizations, we need to shift from a model of one-off measurement to one of evaluative inquiry, conducted by leaders and assisted by evaluation. By understanding evaluation as ongoing, collaborative institutional inquiry, rather than as discrete, outsourced measurement, we can bring it in from the margins to the heart of the foundation enterprise.

Evaluative inquiry is a way for foundation leaders to determine, derive, and develop value in their social interventions. ${ }^{4}$ It helps them process the complex information and knowledge involved in philanthropic work and take advantage of their unique vantage point on the periphery of fields. It works by engaging foundation leaders in conversations that critically explore the tensions and test the assumptions behind program strategy. It moves beyond strategy papers and periodic reports to a more active, iterative, and timely struggle with uncertainty, values, and risk.

These ongoing conversations will ideally focus on seven dynamic dimensions of foundation strategy:

\section{Problem: understanding the need}

2. Purpose: clarifying the desired change

3. Pathway: taking a bet on the best means of achieving desired change based on evidence and experience

4. Practice: acknowledging what we know, what we don't know, and how we might learn more

5. Progress: maintaining regular, systematic, and timely attention on what is being achieved 
6. Proof: identifying evidence needed to make decisions, and then using it

7. Promulgation: sharing with stakeholders what we've done and the difference and discoveries we've made

Conversations about these seven dimensions can and should take place at all levels of the foundation enterprise-between grantmaker and grantee, board member and executive, executive and program officer, program officer and evaluation officer or consultant. In some foundations, they happen now, in bits and pieces, but typically they're considered the responsibility of program and evaluation staff. They aren't systematically happening at the leadership level. Nor do they show the hallmarks of inquiry-open, critical, testing, ongoing, adaptive. The challenge is to create a process and mindset that allows your foundation to explore creative tensions, stay alert to thorny problems, continually test assumptions, and adapt to inevitable change. Our current approach to evaluation doesn't do this. Evaluative inquiry does.

Framed as an intentional application of leadership inquiry to grantmaking practice, evaluation becomes a broad process of examination and assessment of what is known (and not known), rather than a narrow technique of measurement; a tool with application to the many dimensions of the foundation enterprise rather than the province of specialists; and a commonsense approach to thinking about overall foundation effectiveness and accountability. Approaching evaluation as guided, collective inquiry can lead to more accumulated knowledge, more purposeful evaluation, and better information for better decisions. It can galvanize the evaluation conversation within an individual foundation. While short on the bells and whistles of the dashboards and scorecards occupying foundation board and management attention today, the inquiry approach focuses on the everyday dialogue about foundation and grantee effectiveness that makes foundations go. 


\section{Inquiry's Benefits}

This kind of dialogue — early, open, and ongoing_-brings three particular benefits to the grantmaking process.

First, evaluative inquiry allows the foundation staff and board to unpack core assumptions behind each grant or strategy-assumptions that, if off the mark, can undermine grantee success and ultimate foundation impact. There are core assumptions behind all forms of grantmaking, whether one grant, multiple grants, or multiyear initiatives.

Such assumptions take many forms. Often grants are made with bets about the future support of others; "uptake" by government funders often is assumed, and many grantees hold high hopes for continuation support or the capacity to replicate their programs. Many grantees assume that the capabilities (either their own or those of others on whom they depend) to implement their grants are in place, only to find out that such skills are sorely lacking. Other grantees assume that the press will pick up their messages and magnify their communications widely enough that policy change will occur. On the foundation side, assumptions are often reflexively made-but not openly explored-about how grants or strategies advance foundation mission and goals. On the surface, these assumptions might appear harmless, but if any fall through, an entire hypothesized system of change can collapse.

Second, an evaluative inquiry approach surfaces questions early and throughout the grantmaking process. Specifically, it helps program officers determine if they are using research-validated practices in program design, if their approaches have proven effective elsewhere, and if improvements can be made in the future. It supports foundation executives and board members in engaging substantively in a conversation about what works in the programs that they fund. It allows these important stakeholders to approach their roles with a kind of enlightened skepticism early in the evolution of program strategy that only improves the work in the long run.

Third, evaluative inquiry creates a decision trail. In this way, it figures centrally in considerations of overall foundation effectiveness and accountability. Engaging in conversation about the seven strategy dimensions sets the stage to be accountable by allowing others to comprehend the foundation's reasoning, as well as to assess its clarity, the soundness of approaches, and the quality of due diligence applied throughout the grantmaking process. 
More generally, evaluative inquiry has broad applications to the field of philanthropy. It comes into play at:

- Every level of a foundation, especially foundation executive and board member. In fact, it will only succeed if leaders engage in the process.

- Every stage of the grantmaking process: when a foundation articulates its mission, sets strategy, develops new programs, refines programs that are underway, assesses effects once grants are completed, and communicates results across fields and to the general public. It can help to ground foundations in their fields of practice; shed light on the effectiveness of particular interventions; alert foundation staff and grantees to the impact of changes, such as government cutbacks, on programs; and point to "best practices" in a field of endeavor.

- Every type of foundation, not just for foundations with large staff or extensive resources. Whether foundations are big or small, whether they initiate grants or make grants in response to grantee requests, whether they provide project grants, core support, or funding for major initiatives, all foundations can learn to think and work more "evaluatively." 


\section{Implementing Evaluative Inquiry}

Evaluative inquiry should be everyone's job, especially key decisionmakers, and not shuffled off to outside consultants or staff specialists.
What might evaluative inquiry look like at your foundation? As emphasized throughout these pages, it would not be the sole responsibility of your evaluation officer or consultant but part of the charge of other players as well, extending from program staff to management to board members. Evaluative inquiry should be everyone's job, especially key decisionmakers, and not shuffled off to outside consultants or staff specialists. To be sure, the evaluation staff or consultants can play a critical role, contributing and interpreting for leaders relevant models, research, knowledge of best practices, and analysis of previous initiatives and lessons learned.

But the evaluation conversation should be initiated and sustained by foundation leaders. Only through continual questioning of implementation and outcome data can leaders gauge their organization's effectiveness. In this setting, evaluation staff and consultants can do their best work by providing a rich array of evidence regarding policy, practice, changes, and ultimate impact.

\section{Questions for Executives and Board Members}

Not all knowledge comes from research. Serious exchange, observation, and challenge are core competencies for foundation staff engaged in evaluative inquiry. Raising and addressing these questions offers the kind of due diligence that any foundation should conduct in formulating solutions to societal problems. It also allows management and board members to engage in an authentic and serious discussion of the very real difficulties involved in foundation programming.

Executives and board members play a central role in evaluative inquiry. Because they are charged with assessing whether foundation resources are being spent wisely, foundation board members and executives must constantly ask a core question at the very heart of their work: Do the funded programs advance the objectives the foundation is trying to achieve?

As they consider new programs or strategies, board members and managers should consider other questions, such as:

- Do we know what effects to expect from our strategies? How have similar interventions worked in the past, at what scale, and with what populations?

The Evaluation Conversation 
- How is the intervention likely to play out now, under current circumstances and with the population proposed? Why should we choose a new program and how does it differ from what is known about the experience of others?

- Does the program have the right people, the right amount of investment, the right partners, and the right time frame ... and how do we know? In short, how difficult will it be to implement?

- What is the risk of either theory or implementation failure? Has the risk been thought through?

- What important uncertainties exist and do we know enough to confront them well?

- How will foundation staff and grantees know whether the program is working? Will it be possible to make assessments all the way through, and not just at the end, so that program leaders can spot missteps and take corrective action?

- How do our programs "add up" in order to reflect and advance institutional purpose?

- Am I willing to listen and ask hard questions, recognize my own values, and distinguish between what is a question and what is an expression of my values?

- Am I looking for alignment between means and ends?

- Do I recognize that the foundation alone can rarely create change? Do I accept that strong partnerships are almost always needed to tackle important problems? Can I live with the foundation contributing to solutions even if the effects of our support are not isolated?

- How can I productively engage staff in a conversation about real uncertainties?

\section{Questions for Executives in Particular}

- How can I create a climate for productive differences of opinion among the parties? 
- How can I use evaluation to surface voices that I might otherwise not hear? What opportunities can we create to hear opinions other than our own?

- How can I find ways to manage performance in areas where I know little?

- How can I help participants understand the difference between assertions based on values or those based on empirical data? What is an empirically-based judgment versus a valuesbased call?

- Have I reinforced the evaluation conversation with a push for performance? (The effort won't be meaningful unless top management is committed and makes the link with performance.)

- How can we develop a temperament among board members conducive to the kind of lengthy questioning and answers necessary?

\section{A First Step}

How might your foundation begin an evaluative inquiry practice? Consider arranging a preliminary evaluation conversation, ideally one that involves program staff, executives, and board members. You may want to involve a facilitator. Start with a case example, one program that is already under way at the foundation, and experiment with applying the seven evaluative inquiry dimensions (about problem, purpose, pathway, practice, progress, proof, and promulgation).

Following the discussion, take a step back and reflect on how it went. What information would we need to make the conversation better? Who was missing from the room? What other perspectives would have helped? What can we learn from this conversation about the way foundation leaders talk about the institution's business? As you engage in this process, rather than look for the "right" answers (e.g., is the program good or bad?), consider how participants approach the questions and what it might mean for the overall challenge of changing your foundation's evaluation practice.

What's important to remember is that the evaluation conversation begins with asking the seven inquiry questions - and then continuing to ask them. With willingness to share with others the knowledge that results, foundations will make major strides in accounting for what they do, why, and to what end. 


\section{Are You There Yet?}

What would good foundation practice with solid evaluative inquiry at its core look like? How close is your foundation to realizing the promise of this approach to evaluation? Consider your foundation today in light of the following indicators of progress:

- Board members, management, and program staff can articulate the purpose of the foundation in terms of what they would like to accomplish in ten years.

- Board members, management, and program staff can articulate their ideas about best bets for achieving those goals in relation to what is known from past practice and research.

- Board members can engage staff in substantive discussions regarding how grants advance the purpose of the foundation, and foundation staff members are comfortable responding.

- Foundation board members, executives, staff, and grantees all use evaluative inquiry to make decisions.

- With some freshness, staff members are challenging standard operating procedures for how the foundation looks at problems.

- Staff members are looking at what others, such as public and private funders, are doing.

- Board members can tolerate risk in light of their capacity to know their fields and the actors in the field.

- Board members and staff can work with others and understand the essential interdependence inherent in foundation work.

- Grantees are comfortable asking foundation staff why they choose to do some things and not others.

- Board members, executives, and program officers provide the means for grantees to learn as they do and to report this learning to others.

- Foundations publish evaluations for all to see, learn from, and use.

When evaluative inquiry is adequately practiced, board members, executives, and program officers have few worries about accountability because they are able to say what it is that they do and provide good evidence for why they do it. They can show that they work consistently with their fields 
of practice. And they can point to a substantial track record-not only successes but failures, not just innovations and results, but the just-asimportant stories of how their grantees have continued to till the fields, under conditions of both difficulty and reward. 


\section{Endnotes}

1. I'd like to thank Mark Sedway and Abby Spector for their comments, contributions and editorial assistance. The paper has also benefited from the wise feedback and ideas of Beth Bruner of the Bruner Foundation; Susan Conner of the Lumina Foundation for Education; Leila Fiester; Tom Garwin of the Bill and Melinda Gates Foundation; David Hunter of the Edna McConnell Clark Foundation; and Robert Ross of The California Endowment. I also want to acknowledge as an early and important influence Peter Szanton's "Evaluation and the Nonprofit Board," part of the BoardSource Governance Series.

2. Report to Congress and the Non-Profit Sector on Governance, Transparency and Accountability of Charitable Organizations, Panel on the Nonprofit Sector, Washington, DC: Independent Sector, June 2005.

3. Dogged Engineer's Effort to Assess Shuttle Damage, The New York Times, September 26, 2003.

4. Indeed, the notion of evaluation as focusing on leveraging value aligns with the etymology of "evaluate": "ex" (out of) + "value." 


\section{About the Author}

\section{Patricia Patrizi}

Patricia Patrizi, Principal, Patrizi Associates, works with a broad range of nonprofit organizations and philanthropies in the areas of evaluation, strategic planning, and organizational learning. She directed the Practice Matters project and chairs the Evaluation Roundtable, a group of evaluation and program executives at the nation's largest foundations dedicated to improving evaluation practices across philanthropy. She co-edited with Michael Quinn Patton The Spring 2005 New Directions in Evaluation Using the Case Method. Also, she designed, in some part, systems of evaluation and organizational learning for the Rockefeller, Edna McConnell Clark, William Penn, and other foundations.

Previously, she served as Director of Evaluation at the Pew Charitable Trusts for eight years. At Pew, she was responsible for the design and oversight of over 150 evaluations in the fields of health and human services, education, the environment, religion, culture and public policy. Over the last twelve years, she has been the lead evaluator on over 60 projects in the United States, Africa, and Eastern Europe.

Ms. Patrizi holds degrees from Bryn Mawr College and the University of Pennsylvania and was a research fellow at Harvard University. 


\section{PRACTICE MATTERS \\ The Improving Philanthropy Project}

\section{Titles}

Toward More Effective Use of Intermediaries

Peter L. Szanton

Acts of Commission: Lessons from an Informal Study

Janice Nittoli

Toward Greater Effectiveness in Community Change:

Challenges and Responses for Philanthropy

Prudence Brown, Robert J. Chaskin, Ralph Hamilton, and

Harold Richman

Foundation Strategies for Attracting and Managing Talent

Nadya K. Shmavonian

Experienced Grantmakers at Work: When Creativity Comes Into Play Ruth Tebbets Brousseau

Ideas in Philanthropic Field Building: Where They Come from and

How They Are Translated into Actions

Larry Hirschhorn and Thomas N. Gilmore

The Capacity Building Challenge:

A Research Perspective

Paul Light and Elizabeth Hubbard

A Funder's Response

Barbara Kibbe

Communications for Social Good

Susan Nall Bales and Franklin D. Gilliam, Jr.

Philanthropies Working Together: Myths and Realities

Robert Hughes

The Evaluation Conversation: A Path to Impact for

Foundation Boards and Executives

Patricia Patrizi

The Evaluation Conversation 